\title{
Tradición naturalista y museos de historia natural: ¿Qué naturaleza? ¿Cuál historia? Una reflexión desde la historia de la biología
}

Por: Castro Moreno Julio Alejandro ${ }^{1}$

Un día, a fines del siglo XVIII, Cuvier meterá mano a las exquisiteces de museo, las romperá, y disecará toda la conserva clásica de la visibilidad animal. Este gesto iconoclasta, que Lamarck nunca se atrevió a hacer, no traduce una nueva curiosidad por un secreto que no se había tenido ni la preocupación, ni el valor, ni la posibilidad de conocer. Es, lo que resulta mucho más grave, una mutación en el espacio natural de la cultura occidental: el fin de la historia, en el sentido de Tournefort, de Linneo, de Buffon, de Adanson, y también en el sentido en que la entendía Boissier de Souvages al oponer el conocimiento histórico de lo visible al filosófico de lo invisible, de lo oculto y de las causas; y será también el principio de lo que permite, al sustituir la clasificación por la anatomía, la estructura por el organismo, el carácter visible por la subordinación interna, el cuadro por la serie, precipitar hacia el viejo mundo plano y grabado en negro y blanco, los animales y las plantas, toda una masa profunda de tiempo a la cual se le dará el nombre renovado de historia.

Michel Foucault, Las palabras y las cosas.

\section{INTRODUCCIÓN}

Indagar por los diferentes significados que se les han asignado a las palabras "historia" y "naturaleza" puede ser importante para comprender las representaciones que sobre ellas se socializan en los museos de historia natural. ¿Son sinónimos biología y tradición naturalista?, ¿es equivalente hablar de organización y orden?, ¿es la tradición naturalista una perspectiva vigente para guiar la estructuración y el funcionamiento de los museos de historia natural? Éstas y otras preguntas se abordan en el presente ensayo.

Se inicia con una definición de qué se entiende por tradición científica y los tipos de tradiciones que han existido en la biología y, en general, en las ciencias de la naturaleza. Posteriormente se hace una reflexión acerca de las relaciones, distanciamientos y confluencias entre biología e historia natural. En la tercera sección se da cuenta de los imaginarios que a propósito de historia y naturaleza son

${ }^{1}$ Profesor Departamento de Biología, Universidad Pedagógica Nacional. Miembro del Grupo de Investigación Conocimiento Profesional del Profesor de Ciencias.

jcastro@pedagogica.edu.co, alecasmor@yahoo.es 
socializados en los museos de historia natural. En las reflexiones finales se dejan planteadas algunas cuestiones que, se espera, sean objeto de futuros debates.

\title{
¿QUÉ SON LAS TRADICIONES CIENTÍFICAS?
}

Según lo planteado por Suárez (1995, p. 35), una tradición científica es

\begin{abstract}
“(...) la construcción histórica de diferentes tipos de prácticas y habilidades alrededor de diferentes tipos de objetos y fines epistémicos, que no necesariamente son de tipo teórico. La idea de tipos de tradiciones se apoya en el reconocimiento (sustentado empíricamente por numerosos estudios de caso) de que el conocimiento puede corporalizarse en objetos y fines epistémicos tan diversos como las técnicas y artefactos tecnológicos de un laboratorio o las clasificaciones naturales".
\end{abstract}

Dichas tradiciones científicas, continúa Suárez, serían la base para entender tanto el aspecto fragmentado de la ciencia (esto es su caracter localista), como su aspecto integrable. De acuerdo con Martínez (1993a y 1995), en la ciencia existen, al menos, tres tipos de tradiciones: la experimentalista, la teórica y la descriptivista.

A nuestro modo de ver, estas tres clases de tradiciones científicas se pueden ejemplificar a través de la caracterización de cinco tradiciones presentes en la biología de finales del siglo $\mathrm{XIX}^{2}$ que, preliminarmente, hemos identificado ${ }^{3}$. A continuación enunciaremos las tradiciones en mención, pero antes hay que aclarar que la primera la retomamos de la propuesta de Piñero (2001), mientras que las otras cuatro han sido descritas por Raichvarg (1988), a propósito de un estudio histórico sobre la manera en que diferentes "dominios" participaron en la comprensión de los microbios, ó, como él los define, "los seres infinitamente pequeños":

1. La tradición hibridóloga, enfocada principalmente en la horticultura y la ganadería, y preocupada por mejorar el rendimiento de las especies vegetales y animales usadas, sobre todo, para la alimentación de la población humana.

2. La tradición microscopista, cuya principal finalidad era perfeccionar el microscopio y las técnicas de corte, montaje y tinción para dar cuenta de lo que no se podía ver a simple vista, por ejemplo, células de diversos tipos, así como procesos inherentes a ellas.

3. La tradición médica, íntimamente relacionada con el estudio de la anatomía y la fisiología humanas, cuyo fin principal era comprender las causas de las enfermedades para así encontrar sus modos de curación.

${ }^{2}$ Algunas de las cuales, sin duda, tienen sus orígenes en siglos anteriores.

${ }^{3}$ No consideramos que éstas sean las únicas, ni que sean exclusivas de la biología, ni que solamente se hayan evidenciado en el periodo que mencionamos. Igualmente, no entendemos a dichas tradiciones como rejillas inflexibles ni cuadriculas inmutables en las cuales encasillar los trabajos realizados por algunas comunidades científicas. 
4. La tradición química, cuyo interés estaba centrado en identificar las sustancias que componen lo orgánico, así como las reacciones que son particulares de lo vivo, como las fermentaciones.

5. La tradición naturalista, centrada principalmente en describir, recolectar, nombrar y clasificar los "seres de la naturaleza" (entre los cuales se encontraban los seres vivos), clasificaciones y colecciones que se ubican, principalmente, en los museos de historia natural.

Siguiendo con la clasificación que ha hecho Martínez (1995), podríamos arriesgarnos a afirmar que la tradición naturalista sería un ejemplo de tradición descriptivista ${ }^{4}$, mientras que las tradiciones química, médica ${ }^{5}$ y microscopista, ejemplificarían a las tradiciones experimentalistas. Por su parte, creemos que, desde Mendel, la tradición hibridóloga podría ser caracterizada como teórica por la base matemática que hay en sus postulados (posteriormente llamados leyes). Sin embargo, las prácticas de hibridación antes de $\mathrm{Mendel}^{6}$ se acercarían más a un tipo de tradición descriptivista.

Igualmente, es de anotar que las tradiciones científicas no existen en el vacío, es decir que ellas implican un espacio, un tiempo y unos sujetos que las mantienen, las fortifican y las transforman. En ese sentido, asumimos que:

Una tradición científica consiste en una comunidad de científicos sociológica e históricamente identificable. Que la tradición científica es históricamente identificable implica que la comunidad que mantiene la tradición se renueva gradualmente y que, por medio de ese proceso de renovación, se mantienen relativamente constantes, o cambian muy lentamente, los valores y metas de investigación aceptados por la comunidad (Martínez, 1993a, p. 47-48).

En ese orden de ideas, las tradiciones también pueden entenderse como "agrupamientos estables de prácticas con fines compartidos" (Martínez, 2005, p 264). De este modo, podemos ver que las nociones de tradición, comunidad y práctica son indisolubles e, incluso, indistinguibles, ya que al hablar de una de ellas, ya se está implicando a las otras.

Situados en la multidisciplinariedad de la biología contemporánea, podemos afirmar, como lo hace Martínez (1993a, p. 50), que ésta es un complejo de tradiciones científicas que están estrechamente relacionadas, principalmente en lo que a sus objetivos se refiere. Dado lo anterior, nos atrevemos a asegurar que las disciplinas biológicas que hoy existen han surgido

${ }^{4}$ Quizá hasta Darwin, quien trascendió la mera descripción de especies, para plantearse el problema de cómo explicar su origen.

${ }^{5}$ Sobre todo a partir de Bernard.

${ }^{6}$ Incluyendo a Darwin, pues recuérdese que él era colombófilo y tuvo importantes nexos con

horticultores y criadores de animales, nexos que le permitieron hacer su analogía de la selección natural a partir de la selección artificial. 
por procesos de integración de diversas tradiciones provenientes no sólo de la biología, sino de otras ciencias (un claro ejemplo de ello es la biología molecular). Por ello, asumimos que las cinco tradiciones que enunciamos (en su interacción con otras), dieron origen a las comunidades y a las disciplinas que hoy reconocemos como tales.

\title{
TRADICIÓN NATURALISTA Y BIOLOGÍA ¿QUÉ RELACIONES ESTABLECER?
}

De acuerdo con Piñero (2001, p. 367), la biología es una rama del saber que surgió de la síntesis de diversas tradiciones científicas, y si suponemos que ésta es sinónima a la integración de tradiciones de la que habla Suárez (1995), entonces diremos que la biología surgió a través de un proceso de conjunción, entendido como

\begin{abstract}
“(...) diferentes interacciones sociales, técnicas (materiales) y cognitivas entre diferentes tradiciones. Más aún, en ciertas circunstancias histórico-sociales tales interacciones permiten la conformación y consolidación de nuevas disciplinas científicas, de manera que el tipo de integración del conocimiento científico (...) debe ser visto como un proceso de integración de tradiciones en disciplinas y no como un problema de unificación de teorías" (Suárez, 1995, p. 35).
\end{abstract}

Desde una visión ortodoxa, se asume que las disciplinas son "los marcos en los cuales se desarrollan y se justifican las teorías", mientras que desde una nueva postura, las disciplinas se entenderían como la integración de diversas tradiciones a partir de un dominio compartido (Suárez, 1995, p. 38), lo cual es coherente con el hecho de asumir que "Por lo general, las diferentes disciplinas científicas incluyen diferentes tradiciones con objetivos interdependientes" (Martínez, 1993a, p. 50), pero, para saber qué tipo de tradiciones interaccionan en una disciplina, habría que hacer estudios históricos al respecto, por lo que ello se respondería empíricamente (Suárez, 1995, p. 42).

Además de la constitución de un dominio compartido, como aspecto fundamental para la integración de tradiciones en disciplinas, Suárez (1995, p. 43) resalta la importancia de que se establezca un marco institucional, ya que la reproductibilidad de una disciplina demanda el suministro de recursos materiales y sociales, recursos que son facilitados por las instituciones (como centros de investigación, museos, revistas especializadas, laboratorios, escuelas, etc.).

Es de anotar que los dos aspectos señalados (el dominio y el marco institucional), los cuales inciden en la constitución de una disciplina, están estrechamente relacionados y se distinguen, sobre todo, en aras del análisis del proceso de integración de tradiciones. A su vez, hay que decir que los elementos del dominio no son estables, sino dinámicos, $\mathrm{y}$, en ese sentido, generan nuevos problemas al interior de las tradiciones que hacen parte de una disciplina, lo cual se convierte en el núcleo de la propuesta de "re-conceptualizar" la integración de la ciencia. 
Así las cosas, es necesario traer a colación la pregunta que se plantea Suárez (1995), acerca de ¿qué es lo que integra a la ciencia, si un buen número de estudios lo que hacen es destacar el carácter localista de la misma? Frente a este interrogante, la autora en cuestión asume que el asunto no se debe abordar desde la propuesta de unificación de la ciencia a través del establecimiento de relaciones entre teorías, sino que propone entender la integración de la empresa científica por medio de la constitución de disciplinas científicas a partir de las interacciones entre diferentes tradiciones.

Lo anterior nos remite al problema de entender el progreso en la biología como un asunto de diversificación de tradiciones, de su autonomía y de su integración en disciplinas (que también se diversifican), ya que "(...) un aspecto muy importante de la estructura de la ciencia [es] la presencia de una diversidad de tradiciones (presentes en cualquier momento de la historia de la ciencia) que gozan de cierta autonomía entre sí (lo que genera comunicación y acuerdos parciales)" (Martínez, 1993a, p. 42).

Dicho esto, es evidente que estamos contradiciendo una idea muy generalizada: que la biología tiene su origen únicamente en la historia natural, o, dicho de otra manera, que la historia natural se desarrolló para dar origen a la biología. No hay nada más alejado de la realidad que asumir esta idea continuista y acumulativa del desarrollo histórico de una ciencia. Veamos por qué.

Un primer aspecto que queremos desarrollar es ¿a qué denominamos historia natural?, ¿cuál era su objeto de estudio, qué tipo de instituciones eran inherentes a ella, de qué tipo de procedimientos se valía, etc.? Para luego abordar esta pregunta: ¿en qué se asemejan y en qué se diferencian la historia natural y la biología? Vamos por partes.

Según Drouin (1998), no todos los naturalistas eran viajeros, ni todos los viajeros eran naturalistas. Por ejemplo, podemos recordar grandes naturalistas que no hacían expediciones, como Lamarck, cuya actividad estaba centrada, sobre todo, en hacer clasificaciones al interior de museos, jardines botánicos, herbarios, etc. Pero hay que reconocer que "Los inventarios de especies no se elaboran por sí solos. Suponen la existencia de especímenes recogidos, preparados, dibujados, descritos y reunidos en recintos, museos, jardines, herbolarios o gabinetes de historia natural, donde todos puedan verlos, observarlos compararlos... Viajes y colecciones constituyen pues los dos polos de la historia natural" (Drouin, 1998, p. 370).

No obstante, en los inicios de esta tradición, los viajes de los naturalistas no tenían como objetivo principal relatar los aspectos "naturales" de sus travesías, sino que describían en sus crónicas todo cuanto veían y escuchaban (incluso los relatos de los habitantes de las regiones distantes que visitaban). Así, además de dar cuenta de la historia natural de los sitios visitados, los naturalistas también hacían descripciones detalladas de "las ruinas antiguas, los modos de vida, la organización política y religiosa" (Drouin, 1998, p. 366) presentes en las localidades objeto de sus viajes. 
Desde esta perspectiva, no es de extrañar que se aluda a un objeto no diferenciado, es decir, que éste no es abordado desde una "disciplina" específica, sino que se da cuenta de él a partir de un discurso polifacético:

Cuando Aldrovando habla del caballo, describe su forma y aspecto en cuatro páginas. Pero necesita cerca de trescientas para entrar en detalles sobre los nombres del caballo, su cría, hábitat, temperamento, docilidad, memoria, estado afectivo, reconocimiento, fidelidad, generosidad, espíritu de victoria, rapidez, agilidad, capacidad prolífica, simpatías, antipatías, enfermedades y tratamiento; tras esto vienen los caballos monstruosos, los caballos prodigiosos, los caballos fabulosos, los caballos célebres, con descripción de los lugares donde se hicieron famosos, el papel de los caballos en la equitación, en el transporte, en la guerra, en la caza, en los juegos, en las faenas del campo, en los desfiles, la importancia del caballo en la historia, en la mitología, en la literatura, en los proverbios, en la pintura, en la escultura, en las medallas, en los blasones (Jacob, 1999, p. 34).

Nos encontramos, entonces, no ante una historia natural, sino frente a diversas historias que, incluso, podríamos llamar fábulas: "Lo que existía en el siglo XVI y hasta mediados del XVII eran historias (...) La historia de un ser vivo era ese mismo ser, en el interior de esa red semántica que lo enlaza con el mudo" (Foucault, 1998, p. 129). Esta perspectiva es denominada por Valencia (1989, p. 20) como una "episteme de la semejanza", y esto es así debido a que se asume que todo en la naturaleza está relacionado, todo es naturaleza y la naturaleza es una (Jacob, 1999, p. 33), de ahí que las semejanzas sean una prueba de dicha unicidad.

Así las cosas, no es de extrañar que los relatos de los historiadores naturales dieran cuenta de híbridos inimaginables y, del mismo modo que es posible hablar de hojas acorazonadas, no es increíble la descripción de un animal con orejas y patas de perro, hocico de cerdo, cola de rata y caparazón de tortuga ${ }^{7}$. De este modo, es evidente que los signos hacen parte de las cosas (Valencia, 1989, p. 21), que los seres son indistinguibles de las palabras que los describen, en fin, es inevitable reconocer que las fábulas son inherentes a los seres de la naturaleza o, dicho de otro modo, que la historia de la naturaleza es la suma de las fábulas que sobre los seres se han escrito.

Otra evidencia de esa unicidad de la naturaleza es su continuidad, aspecto éste que se materializa en la escala de la naturaleza (scala naturae), en donde se aprecia una gradación que va desde los minerales más toscos, hasta los animales más perfectos, pasando por las plantas y

${ }^{7}$ Especulando un poco, es probable que esta descripción sea parecida a las primeras que se hicieron de los armadillos encontrados en las expediciones realizadas por europeos que nunca antes habían visto a este animal. 
los animales primitivos ${ }^{8}$. Así, pues, es notable que el objeto de la historia natural no eran los organismos, sino en general, los seres (incluyendo los no vivos, es decir, los minerales). Aunque esta forma de asumir el objeto de la historia natural no se modificó sustancialmente, la perspectiva de las fábulas sí tuvo un cambio significativo:

[En la segunda mitad del siglo XVII] los cuerpos vivientes se pulimentan, por así decirlo. Se desprenden de su capa de analogías, semejanzas y signos para aparecer con la desnudez de las líneas y superficies que la mirada reconoce. Ya no es posible situar en un mismo plano la forma de una planta o un animal y las ideas que puedan tener acerca de ellos los viajeros, los historiadores o los juristas. Lo que se lee y lo que se oye no puede igualarse con aquello que se ve. El aspecto de los seres vivos y su estructura visible se convierten entonces en objeto de análisis y clasificación (Jacob, 1999, p. 39).

Desde esta óptica, que podemos identificar, por ejemplo, con Linneo, cobra un valor importante aquello que se puede ver y que es susceptible de ser medido y descrito sin temor a caer en subjetividades (como cuando se describen sabores, olores y sonidos). Asimismo, los dibujantes (personajes imprescindibles en la tradición naturalista, especialmente en los viajes) adquieren un papel protagónico en la representación (lo más fiel posible) de aquello que se observa y que se desea resaltar. En este orden de ideas, según Jacob, el objeto de estudio de la historia natural será la estructura visible, entendida como todos aquellos rasgos que no escapan a la mirada del naturalista. De este modo, "La vieja red de similitudes es sustituida por las comparaciones. El conocimiento de las cosas se fundamenta en sus relaciones, sus identidades y sus diferencias" (Jacob, 1999, p. 53).

Nos hallamos, entonces, en el interior de una nueva perspectiva: "la episteme de la representación" en la cual se liberan a los seres de las palabras que hacen de su historia una fábula, para representarlos desnudos ante el análisis de la razón, lo cual permite describirlos con un nuevo lenguaje (Valencia, 1989, p. 22). De este modo, Linneo hace en la historia natural algo análogo a lo que hizo Lavoisier en la química: creó una nomenclatura. Ambos proyectos tienen semejanzas importantes de destacar. Lavoisier propone unos nombres elementales que, al combinarse, originan los nombres compuestos, y dicha nominación pone fin a una serie de nombres diversos que daban cuenta de las sustancias. El nuevo lenguaje químico se hace universal y entendido por todos los que practiquen esa ciencia. Por su parte, la nomenclatura linneana rompe con las fábulas en las que estaban inmersas las descripciones de los seres. Ahora, los nombres dan cuenta del carácter o caracteres que son visibles y representativos de una especie: "La denominación de esta visibilidad, que los botánicos llamaron estructura, constituye un campo en el cual la Historia Natural, a partir del siglo XVII libre ya de la superstición y la magia, elaborará un lenguaje fundamentalmente taxonómico de los SERES" (Valencia, 1989, p. 22-23).

8 Para algunos defensores de dicha escala, ésta culminaba con el ser humano, pero para otros este ascenso iba más allá, ya que después de la humanidad se encontraban los ángeles, arcángeles, etc., y finalizaba en la mayor perfección posible: Dios. 
las cosas, el describir, dar nombre y clasificar, permite que se transformen los museos, los jardines botánicos, los herbolarios $\mathrm{y}$, hasta, los libros, ya que es teóricamente posible saber si una planta o un animal pertenecen a una especie conocida, o si es necesario fundar una nueva (Drouin, 1998, p. 371). Por ello, las colecciones adquieren un orden taxonómico, que trasciende la mera perspectiva de ubicar los especímenes en unos estantes estéticamente configurados, sino que lo que ahora importa es crear unas categorías teóricas para clasificar los seres. Ya no se trata de hallar relaciones de continuidad y de semejanza, ahora la diferencia es la que tiene la palabra. Asistimos, así, a una mutación en la estructura de la naturaleza.

No obstante, esta perspectiva aún no tiene en cuenta el tiempo como un parámetro inherente a los seres. Serán Lyell y otros, quienes darán cuenta de un tiempo geológico más extenso del que admitían las lecturas literales de las Sagradas Escrituras. Asimismo, serán Darwin y Wallace (y antes de ellos Buffon y Lamarck) quienes asumirán la transformación de los organismos a través de vastos periodos de tiempo. Ni la Tierra, ni los organismos que la habitan, han sido siempre como los conocemos, tienen una historia, han estado a merced del tiempo. Sin embargo, hay que recordar lo que nos anunciaba Foucault en el epígrafe, y es que para entender ese nuevo tiempo histórico de los seres, había que trascender el ordenamiento de las clasificaciones y situarse en la organización interna de los seres, había que hacer el tránsito de lo visible hacia lo oculto, ir de las formas a las causas.

Linneo y otros naturalistas produjeron las categorías en las cuales instalaron a los seres, pero esas categorías, al igual que los individuos que contienen, siempre han sido así, fueron creadas de una vez y para siempre. ¿Qué historia se le puede atribuir a un ser que no se transforma? ¿Qué papel puede desempeñar el tiempo para dar cuenta de unas clases inmutables? Nos encontramos aún en una historia natural que no tiene en cuenta la historia de la naturaleza (incluyendo la historia de los seres vivos).

Es principalmente desde Darwin que el factor tiempo se hace indisociable de los organismos, es desde entonces que existe una historia natural digna de ser llamada así. Es desde esa época que las especies tienen un origen natural, unas bifurcaciones y también una extinción. La creación ya no puede ser perfecta, sencillamente porque en la naturaleza no hay criaturas, sino organismos. Las criaturas fueron puestas en un escenario diseñado para ellas, los organismos se desarrollan en un entorno y lo afectan a la vez que son afectados por éste: entorno y organismos son, pues, entidades históricas que se relacionan y se transforman de múltiples maneras. La contingencia ha reemplazado al plan divino. La historia es contingente a la vez que la contingencia es histórica, y esta idea es totalmente opuesta a un mundo fijo, creado y predestinado a cumplir un fin. La tradición naturalista de Linneo no es histórica, mientras que la de Darwin sí:

(...) la novedad radical de El origen de las especies consistía en que el tiempo no era entendido como un poder, sino que se lo percibía directamente en efectos en apariencia distintos pero en realidad unificados por su complementariedad. El 
fósil era el tiempo petrificado; el embrión era el tiempo en acción; el órgano rudimentario era el tiempo retrasado. Unos y otros conformaban los archivos de la organización actual, donde el biólogo procuraba establecer un comienzo por superposición de lecturas. En el archivo paleontológico, el comienzo estaba en lo más bajo; en el embriológico, el comienzo estaba en lo más común; en el morfológico, el comienzo estaba en lo más reducido. A partir de aquí, la vieja anatomía comparada podía remozarse. El árbol genealógico no procedía de la sistemática sino que le daba un soporte. El antepasado común reemplazaba al arquetipo. La clasificación cesaba de ser una pintura de las formas coexistentes para devenir un cañamazo sinóptico tejido con los hilos del tiempo (Canguilhem, 2005, p. 135-136).

De acuerdo con Darwin (citado por Hacking, 2006, p. 7-8), los naturalistas se han esforzado por ordenar las especies en diversas categorías, dentro de lo que se ha llamado el "sistema natural", sin tener bien claro en qué consiste, por lo que Darwin sostiene que "Toda verdadera clasificación es genealógica" y se basa en comunidades de descendencia. Desde esta perspectiva, “(...) nous sommes à peu près d'accord sur ce qui fait qu'un groupe biologique est un groupe naturel: la généalogie. Les espèces ont cessé d'être des objets représentant la nature en termes de ressemblance. Elles sont devenues des objets historiques"9 (Hacking, 2006, p. 8).

Llegados a este punto, consideramos que ya estamos en capacidad de reafirmar por qué la biología no es una continuidad de la historia natural. Si colocamos en un solo saco a todos los naturalistas que existieron, habrá rupturas y continuidades entre historia natural y biología. Por ejemplo, dentro de las continuidades, encontramos la nomenclatura linneana, la perspectiva histórica de Darwin y la palabra "Biología” propuesta por Lamarck (y otros, a principios del siglo XIX). Si nos situamos en el terreno de las rupturas, diremos que hay una discontinuidad entre el objeto de la historia natural y el de la biología: en la primera, su objeto estaba representado por todos los seres de la naturaleza (incluyendo los inertes), mientras que en la segunda, su objeto se caracteriza por ser un sistema de sistemas vivientes. El objeto de la historia natural da cuenta de lo visible, el de la biología da cuenta de relaciones que escapan a la mirada, relaciones que, según Jacob (1999), estarían representadas por la organización.

Vemos, de este modo, que organización y orden no pueden ser sinónimos en el ámbito del que estamos hablando. La organización se expresa en una serie de interacciones, procesos, relaciones y funciones que hacen del sistema viviente lo que es. La ordenación quiere establecer una lógica de categorías jerárquicas en la naturaleza. A la historia natural le interesan las diferencias que le permitan clasificar a los seres en diversos grupos, mientras que la biología se preocupa por comprender qué tienen en común los seres que llamamos vivientes (Jacob, 1999); a esta ciencia le interesa comprender qué es lo que hace vivo a un organismo. Así

${ }^{9}$ (...) estamos, más o menos, de acuerdo sobre aquello que hace que un grupo biológico sea un grupo natural: la genealogía. Las especies han dejado de ser unos objetos que representan la naturaleza en términos de semejanza. Ellas han devenido en objetos históricos. (La traducción es nuestra). 
las cosas, es innegable que entre historia natural y biología hay diversas y complejas rupturas y continuidades. Por lo tanto, tenemos que reconocer con Canguilhem que

A menudo el investigador de rupturas cree, a la manera de Kant, que un saber científico se inaugura con una ruptura única, genial. A menudo también el efecto de ruptura es presentado como un efecto global que afecta la totalidad de una obra científica. Sin embargo, habría que saber detectar en la obra de un mismo personaje histórico rupturas sucesivas o rupturas parciales. Ciertos hilos de una trama teórica pueden ser completamente nuevos, mientras que otros han sido sacados de texturas antiguas (2005, p. 32-33).

Es decir que la biología no tiene su origen exclusivamente en la historia natural, pero dicho origen sí retomó algunos aspectos de esa perspectiva. Como mostramos párrafos atrás, nos parece más prudente reconocer que la biología se institucionalizó por medio de la integración de diferentes tradiciones, dentro de las cuales la naturalista es sólo un ejemplo. En ese sentido, hacer una historia de la biología implica reconocer que esta ciencia no existía antes del siglo XIX, y que no es una hija legítima de la historia natural:

Se quieren hacer historias de la biología en el siglo XVIII, pero no se advierte que la biología no existía y que su corte del saber, que nos es familiar desde hace más de ciento cincuenta años, no es válido en un periodo anterior. Y si la biología era desconocida, lo es por una razón muy sencilla: la vida misma no existía. Lo único que existía eran los seres vivientes que aparecían a través de la reja del saber constituida por la historia natural (Foucault, 1998, p. 128).

\section{MUSEOS Y TRADICIÓN NATURALISTA: DIFERENTES REPRESENTACIONES DE HISTORIA Y NATURALEZA}

Hemos visto que dentro de las tradiciones que describimos al inicio de este escrito, es en la naturalista en donde los museos tienen un papel preponderante. Igualmente hemos notado que, sobre todo a partir de una perspectiva taxonómica de los seres, la historia natural precisa de nuevos lugares en los cuales materializar sus clasificaciones, es decir, que se requieren sitios específicos en donde sus colecciones devengan en sistematizaciones. Esos sitios han sido los museos, los jardines y los gabinetes, principalmente.

De acuerdo con Jhan, Löter y Senglaub (1989, p. 234), la creación de este tipo de instituciones se hizo para sistematizar el conocimiento de la naturaleza, expresar el ordenamiento conceptual y exponer el orden universal. Asimismo, continúan estos autores, los grandes naturalistas del siglo XVIII fueron a la vez fundadores, administradores o clasificadores científicos de importantes museos. De este modo, tanto las instituciones como las actividades que giraban en torno a ellas, permitieron que las prácticas y las teorías de la historia natural se independizaran de la medicina, pues recuérdese que importantes naturalistas, como Linneo, tenían formación 
de médicos, lo cual hacía que el estudio de la botánica (y de otras ramas del saber) estuviera centrado en comprender las propiedades curativas de los especímenes estudiados.

De igual manera, y en especial a partir de finales del siglo XVIII, los museos se convirtieron en centros de enseñanza. Tal es el caso del Musée National d'Histoire Naturelle, del cual uno de sus fundadores fue Lamarck, y en el que se llevaron a cabo nueve cátedras relacionadas con diferentes aspectos de la historia natural, principalmente de la botánica y la zoología (Jhan, Löter y Senglaub, 1989, p. 255).

Asimismo, hay que destacar que las colecciones presentes en los museos se vieron altamente enriquecidas por una tendencia europea que podríamos denominar colonialista. Es de recordar que las grandes expediciones fueron financiadas por los imperios europeos, cuya principal finalidad era la de inventariar los "recursos" con los cuales éstos disponían y que sus colonias les brindaban. Un ejemplo de nuestro contexto es el de Mutis y la expedición botánica del Nuevo Reino de Granada, llevada a cabo a finales del siglo XVIII. En ese sentido, en los museos se muestran la riqueza de los estados y el poder que tienen para apropiarse de ella. Así pues, el museo tiene una finalidad claramente ideológica, en el sentido de que, implícita o explícitamente, se le dice a la población quiénes dominan y quiénes son dominados: “ $O$ tamanho do museu de uma nação era um índice de seu poder colonial, a força e extensão política da nação determinava o olhar que emolduraria a visão de natureza"10 (Lenoir, 1997, p. 65).

En ese sentido, y de acuerdo con Findlen (1994, p. 1), al inicio de la modernidad europea, las colecciones de los museos tienen como principal propósito traer toda la naturaleza al interior de un solo espacio. Siguiendo con Findlen, podemos añadir que, en dicha época, "Possessing nature was part of a more widespread delight in collecting objects of scientific worth"11 (p. 2) "Collecting, in short, had become an activity of choice among the social and educated elite. It filled their leisure hours and for some seemed to encompass every waking moment of their lives. Through the possession of objects, one physically acquired knowledge, and through their display, one symbolically acquired the honor and reputation that all men of learning cultivated"12 (p. 3). A su vez, dichas colecciones se exhibían en los museos como un continuo, aspecto que es consecuente con la visión de naturaleza que tenían los naturalistas (recuérdese la idea de la scala naturae).

10 “El tamaño del museo de una nación era un índice de su poder colonial, a fuerza y extensión política de la nación determinaba la forma de observar que encuadraría la visión de naturaleza." (La traducción es nuestra).

${ }^{11}$ Poseer la naturaleza era parte de un deleite más extendido en coleccionar objetos de valor científico (La traducción es nuestra).

12 "Coleccionar, brevemente, se habían vuelto una actividad de opción entre la élite social y educada. Dicha actividad llenaba las horas de ocio, y para algunos parecía abarcar cada momento de su vida en los que se hallaban despiertos. A través de la posesión de objetos, uno adquiría conocimiento físicamente, y a través de la exhibición de aquéllos, uno simbólicamente adquiría el honor y la reputación de todos los hombres de aprendizaje culto. (La traducción es nuestra). 
Quisiéramos retomar en este momento lo que discutimos en la sección anterior acerca del papel del tiempo en la historia natural, para relacionarlo con la forma en que se expresa la naturaleza en los museos. En primer lugar, desde una perspectiva de las historias, es decir de las fábulas, la naturaleza se expresa como una unicidad de formas que se entrelazan de acuerdo con las crónicas que a su alrededor se tejen:

Se ha dicho con frecuencia que la constitución de los jardines botánicos y las colecciones zoológicas traducía una nueva curiosidad por las plantas y las bestias exóticas. De hecho, desde mucho tiempo atrás, éstas habían llamado la atención. Lo que ha cambiado es el espacio en el que se puede verlas y desde el cual se puede describirlas. En el Renacimiento, la extrañeza animal era un espectáculo; figuraba en las fiestas, en las justas, en los combates ficticios o reales, en las reconstituciones legendarias en las que el bestiario desarrollaba sus fábulas sin edad. El gabinete de historia natural y el jardín, tal como se les ha instalado en la época clásica, sustituyen el desfile circular de "especimen" por la exposición en "cuadro" de las cosas. Lo que se ha deslizado entre estos teatros y este catálogo no es el deseo de saber, sino una nueva manera de anudar las cosas a la vez con la mirada y con el discurso. Una nueva manera de hacer la historia (Foucault, 1998, p. 132).

Desde esta óptica que podríamos denominar linneana, la historia de la naturaleza se reduce a la descripción objetiva de las estructuras visibles, historia que se narra a partir del lenguaje taxonómico, que a su vez da cuenta del fijismo de las especies. Hay que añadir que, desde este punto de vista, la naturaleza sigue siendo un continuo y las diferencias entre los seres es lo que permite el establecimiento de grupos jerárquicos: " $Y$ en este tiempo clasificado, en este devenir cuadriculado y especializado emprenderán los historiadores del siglo XIX la tarea de escribir una historia finalmente «verdadera»-es decir, liberada de la racionalidad clásica, de su ordenamiento y de su teodicea, restituida a la violencia irruptora del tiempo" (Foucault, 1998, p. 132).

A partir de esta mutación, y desde la propuesta darwiniana, es que se asume la naturaleza como discontinua e histórica, pero aunque la historia de la Tierra y la historia de los organismos confluyen, no son la misma: las transformaciones de los organismos no se pueden deducir únicamente a partir de los cambios geológicos.

Según Lenoir (1997), nosotros tendemos a suponer que nuestros museos de historia natural son "templos de Darwin", es decir que allí se ponen en evidencia sus aportes, sin embargo, continúa él, esto sólo ocurre de "boca para afuera", ya que sigue predominando una idea de evolución marcada por el progreso teleológico y no por la contingencia histórica, propia de la propuesta de la selección natural. Esta idea es reforzada por MacFadden (2008, p. 589) quien dice que "Visitors to natural history museums have an incomplete understanding of evolution. 
Although they are relatively knowledgeable about fossils and geological time, they have a poor understanding of natural selection"13.

Así las cosas, es de esperar que este cambio en las concepciones de la naturaleza y su historia se vean reflejadas en la manera en que éstas se "representan" en los museos. Sin embargo,

(...) as exposições do museu são superiores à experiência direta da natureza. Por sua seleção, justaposição e ordenamento dos elementos ("como as coisas ficam mais refinadas em conjunto do que isoladas"), o museu, embora seja um fragmento, evoca a experiência do significado e variedade da natureza de maneira mais completa do que a própria natureza. As exposições não apresentam a própria natureza, mas em vez disso, ícones para meditação e estudo. A natureza (...) é um texto, um signo a ser lido mais convenientemente dentro da moldura do hall de exposição (Lenoir, 1997, p. 57) ${ }^{14}$.

A esta situación hay que añadir que, las clasificaciones en los museos no son ajenas a las teorías (e intereses y finalidades) que las sustentan. Como lo afirma Lenoir: "(...) a representação de tais entidades privilegiadas como natureza, em tais locais privilegiados como os museus, é sempre marcada pelos interesses das pessoas que fazem a representação; isto contribui para a projeção dos interesses humanos sobre a natureza: a «naturalização»-e portanto, contribui para o privilégio e a universalização de interesses políticos específicos ${ }^{15}$ (1997, p. 56). Entonces, con Lenoir, podemos decir que en los museos de historia natural no se representa la naturaleza, sino que se pone de manifiesto la imagen de naturaleza que se quiere presentar y transmitir al público. En este orden de ideas, y según lo afirmado por Hacking (2006):

Les chercheurs, au laboratoire, ne font pas qu'observer le monde: ils changent le monde, ils interviennent dans le cours de la nature. Ils ne se contentent pas d'enregistrer des observations sur les événements naturels. Ils modifient le

${ }^{13}$ Los visitantes de los museos de historia natural poseen una comprensión incompleta de la evolución. Aunque ellos son relativamente conocedores de los fósiles y del tiempo geológico, tienen una pobre comprensión de la selección natural. (La traducción es nuestra).

14 (...) las exposiciones del museo son superiores a la experiencia directa de la naturaleza. Por su selección, yuxtaposición y ordenamiento de los elementos ("como las cosas quedan más refinadas en conjunto que aisladas"), el museo, aunque sea un fragmento, evoca la experiencia del significado y variedad de la naturaleza de manera más completa que la propia naturaleza. Las exposiciones no presentan la propia naturaleza, sino, en cambio, íconos para meditación y estudio. La naturaleza (...) es un texto, un signo a ser leído más convenientemente dentro del marco del hall de exposición (La traducción es nuestra).

${ }^{15}$ la representación de tales entidades privilegiadas como naturaleza, en tales locales privilegiados como los museos, está siempre marcada por los intereses de las personas que hacen la representación; esto contribuye para la proyección de los intereses humanos sobre la naturaleza: la «naturalización» -y por lo tanto, contribuye al privilegio de la universalización de intereses políticos específicos. (La traducción es nuestra). 
monde, ils modifient l'univers. Ils ne font pas que signaler les phénomènes, ils les créent. Oui, dans un laboratoire, on crée des phénomènes. Des phénomènes qui $\mathrm{n}^{\prime}$ avaient pas de existence avant leur création par les chercheurs (p. 12) ${ }^{16}$.

Así como en los laboratorios los fenómenos son creados, más que descritos, Lenoir afirma que en los museos ocurre una situación análoga: "Os museus produzem a natureza com seus laboratórios, salas de depósito dos materiais e equipes de taxidermistas, artistas e curadores. E eles produzem a natureza nos museus à luz de interesses específicos (...) envolvendo, entre outras coisas, política e economia" (1997, p. 59) ${ }^{17}$.

Si es la naturaleza la que es representada en las colecciones de los museos de historia natural, hay que preguntarse acerca de qué naturaleza estamos hablando. Consideramos que dichos procesos de naturalización de los ejemplares de los museos debe hacerse explícita, para que los visitantes sean conscientes de que lo que allí se les muestra no es la naturaleza, sino un ícono de ella.

\section{REFLEXIONES FINALES}

Sin duda, es Bachelard uno de los filósofos de la ciencia que más nos ha invitado a asumir una actitud crítica frente a los progresos de la actividad científica, y, en buena medida, este aspecto es central en lo que él denominó "la formación del espíritu científico". En este orden de ideas, en una conferencia pronunciada en 1951, el filósofo francés hizo una aseveración muy importante para el tema que nos ocupa: mientras que la curiosidad natural se interesa por ver, la curiosidad científica se esfuerza por comprender (Bachelard, 1980, p. 129). Dado que la conferencia que hemos mencionado fue pronunciada en Le Palais de la Découverte ${ }^{18}$, Bachelard le anuncia a su auditorio que a ese lugar no se debe ir para ver, sino para comprender, ya que aquél "no es un museo para mirones. Uno no debe pasearse por él un día de lluvia, para pasar el rato o para matar el tiempo. Se debe venir a trabajar. A trabajar su espíritu. Al comprender la ciencia en su novedad, se viene para hacerse un espíritu nuevo" (Bachelard, 1980, p. 129).

${ }^{16}$ Los investigadores, en el laboratorio, no sólo observan el mundo: cambian el mundo, intervienen en el curso de la naturaleza. Ellos no se contentan con registrar las observaciones sobre los eventos naturales. Ellos modifican el mundo, ellos modifican el universo. Ellos hacen más que señalar los fenómenos, los crean. Sí, en un laboratorio, nosotros creamos los fenómenos. Unos fenómenos que no tenían existencia antes de su creación por parte de los investigadores. (La traducción es nuestra).

17 "Los museos producen la naturaleza con sus laboratorios, salas de depósito de los materiales y equipes de taxidermistas, artistas y curadores. Y ellos producen la naturaleza en los museos a la luz de intereses específicos (...) involucrando, entre otras cosas, política y economía. (La traducción es nuestra).

${ }^{18}$ El Palacio del Descubrimiento es un museo y centro cultural-científico, ubicado en París. Fue fundado, en 1937, por el Premio Nobel de Física Jean Perrin. 
Desde este punto de vista, nos preguntamos ¿qué motiva a las personas a visitar los museos de historia natural? Sin embargo, también es justo volver a cuestionarnos acerca de ¿qué tipo de representaciones sobre la naturaleza son las que se socializan en dichos lugares?

Permítasenos hacer una analogía para volver sobre este punto. En el idioma inglés es clara la diferencia entre History y Story. La primera de ellas denota la historia como un discurso científico, mientras que la otra se podría equiparar a las fábulas a las que aludimos párrafo atrás. La tradición naturalista antes de Darwin, es una perspectiva carente de Historia (History), ya que se cuentan fábulas o historias (stories) de la naturaleza, pero no se tiene en cuenta la historia de la naturaleza. Un museo de historia natural que carezca de su aspecto histórico, es un lugar apto para los mirones que mencionaba Bachelard. Por su parte, un museo que tenga en cuenta la historicidad evolutiva de los organismos, podría propiciar la formación de un espíritu científico.

Para cerrar, vamos a plantear un asunto que sólo quedará como eso, como una propuesta que no desarrollaremos aquí. Si nos declaramos darwinistas, y si nos instalamos en la actualidad de la biología ¿no sería anacrónico seguir hablando de museos de historia natural, dado que la naturaleza es más amplia que los organismos que hacen parte de ella y porque dicha tradición ya ha sido reevaluada?

¿No deberíamos, más bien, reemplazar la nominación de historia natural de los seres, por una historia evolutiva de los organismos? $\mathrm{Si}$ bien es cierto que por su papel y por sus características, en los museos se inmovilizan los especímenes, lo que podría dar a entender que el tiempo se ha detenido, ¿no sería, al menos, oportuno impedir que ellos inmovilicen las ideas y las comprensiones de una naturaleza dinámica?

En este escrito hemos querido mostrar que cuando decimos "historia natural", no es muy claro a qué historia y a qué naturaleza nos estamos refiriendo. La historia y la filosofía de la biología pueden ser grandes aliados a la hora de representar, en los museos, la historia de los organismos en su curso natural y la naturaleza viviente en su devenir histórico.

\section{Bibliografía}

- BACHELARD, G. 1980 [1973] La actualidad de la historia de la ciencia. BACHELARD, G. El compromiso racionalista.: Siglo XXI, México D.F.

- CANGUILHEM, G. 2005. [1988]. Ideología y racionalidad en la historia de las ciencias de la vida. Nuevos estudios de historia y de filosofía de las ciencias. Amorrortu, Buenos Aires.

- DROUIN, J-M. 1998. De Linneo a Darwin: los viajeros naturalistas.. En: SERRES, M (editor). Historia de las ciencias. Cátedra, Madrid. p. 363-379

- FINDLEN, P. 1994. Possessing nature. Museums, collecting, and scientific culture in Early Modern Italy. University of California Press, Los Angeles.

- FOUCAULT, M. 1998. [1968]. Las palabras y las cosas. 26 ed. Siglo XXI, México D.F. 
- HACKING, I. 2005. Méthodes de raisonnement. Disponible en http://www.college-defrance.fr/media/ins pro/UPL32424 raisonnement.pdf

- HACKING, I. 2006. Des classifications naturelles. Disponible en: http://www.college-defrance.fr/media/ins pro/UPL32428 classifications naturelles.pdf

- JACOB, F. 1999. [1970]. La lógica de lo viviente. Una historia de la herencia. Tusquets, Barcelona.

- JHAN, I., LÖTER, R., Y SENGLAUB, K. 1989. Historia de la biología. Teorías, métodos, instituciones y biografías breves. Labor, Barcelona.

- LENOIR, T. (1997). A ciência produzindo a natureza: o museu de história naturalizada. En Episteme, Porto Alegre (Brasil), 2 (4): 55-72. Disponible en: http://www.ilea.ufrgs.br/episteme/portal/

- MacFADDEN, B. 2008. Evolution, museums and society. Trends in Ecology and Evolution, 23 (11): 589-591.

- MARTÍNEZ, S. 1993a. Método, evolución y progreso en la ciencia (1ª Parte). Crítica, Revista Hispanoamericana de Filosofía (México), 25 (73): 37-69.

- MARTÍNEZ, S. 1995. La autonomía de las tradiciones experimentales como problema epistemológico. Crítica, Revista Hispanoamericana de Filosofía (México), 27 (80): 3-48.

- MARTÍNEZ, S. 2005. La geografía de la razón científica: dependencia epistémica y estructura social de la cognición. p 249-290 En: MARTÍNEZ, S., Y GUILLAUMIN, G. (compiladores). Historia, Filosofía y Enseñanza de las Ciencias. Universidad Nacional Autónoma de México e Instituto de Investigaciones Filosóficas, México D.F.

- PIÑERO, D. 2001. La tradición de los hibridólogos en los siglos XVIII y XIX. La teoría celular y su influencia en el nacimiento de la biología. p 367-378 En: BARAHONA, A, SUÁREZ, E, Y MARTÍNEZ, S. (compiladores). Filosofía e historia de la biología. Universidad Nacional Autónoma de México, México D.F.

- RAICHVARG, D. 1988. Hacia la comprensión de los seres infinitamente pequeños. p. 65-123. En: GIORDAN, A., RAICHVARG, D., DROUIN, J-M., GAGLIARDI, R., y CANAY, A. M. Conceptos de biología. Tomo 1: La respiración. Los microbios. El ecosistema. La neurona. Labor, Barcelona.

- SUÁREZ, E. 1995. De la unificación de teorías a la integración de disciplinas. En: Diánoia, Anuario de filosofía (México), (41): 33-52.

- VAlENCIA, S. 1989. La biología: ¿ciencia de la vida o ciencia de lo vivo? Análisis de las condiciones epistemológicas que hicieron posible pensar los determinantes del fenómeno vivo como el objeto de la biología. Bogotá, Publicaciones de la Universidad Pedagógica Nacional. 